\title{
Determinantes da adesão ao tratamento anti-retroviral em Brasília, DF: um estudo de caso-controle
}

\author{
Determinants of antiretroviral treatment adherence in Brasília, Federal District: \\ a case-control study
}

\author{
Cláudio Viveiros de Carvalho', Edgar Merchán-Hamann² e Raul Matsushita ${ }^{3}$
}

\begin{abstract}
RESUMO
Buscou-se avaliar os fatores relacionados à adesão ao tratamento anti-retroviral no Distrito Federal. De 150 pacientes entrevistados em sete centros de referência, 35 não aderentes foram definidos como casos, sendo selecionados 70 controles aderentes, pareados por idade. Avaliaramse variáveis sócio-demográficas, hábitos, suporte social, qualidade de vida, questões relacionadas a doença, estado clínico, tratamento e serviço. Na análise bivariada, houve associação da adesão com raça/cor, escolaridade, centros de referência em que faz acompanhamento e renda familiar. Após ajuste, cor parda, centros de referência localizado no Plano Piloto, escolaridade alta e receber apoio dos amigos quanto às necessidades permaneceram associados com adesão. Retirando raça/cor do modelo, mantiveram-se centros de referência, escolaridade, profissão, renda, apoio (contar com alguém que demonstre gostar de você) e satisfação com o atendimento na farmácia de dispensação. Além dos fatores já consolidados na literatura, questões relacionadas ao apoio no âmbito micro-social e aos serviços de assistência mostraram-se associados à observância terapêutica.
\end{abstract}

Palavras-chaves: Adesão. Observância terapêutica. HIV. Aids.

\section{ABSTRACT}

We sought to evaluate factors relating to adherence to antiretroviral treatment in the Federal District. Out of 150 patients interviewed at seven reference centers; 35 non-adherent subjects were considered to be cases; we selected 70 age-matched adherent individuals as controls. Variables relating to sociodemographics, habits, social support, quality of life, disease-related issues, clinical conditions, treatment and healthcare services were evaluated. Bivariate analysis showed that adherence was associated with race/color, educational level, the reference center where the patient was followed up and familial income. After adjustments, mixed race (parda), reference center location in central Brasilia, high educational level and friends' support for needs remained associated with adherence. After excluding race/color from the model, the reference center location, educational level, profession, income, support (being able to count on someone who demonstrably likes you) and satisfaction with the service at the pharmacy remained related to adherence. In addition to the factors already established in the literature, questions relating to support within the microsocial environment and the healthcare services were shown to be associated with therapeutic compliance.

Key-words: Adherence. Therapeutic compliance. HIV. Aids.

Uma das principais questões atuais em relação à epidemia de Aids diz respeito à possibilidade de os pacientes seguirem 0 tratamento da forma como foi prescrito. Os esquemas terapêuticos disponíveis proporcionam melhora clínica e laboratorial importantes para o paciente; no entanto, vários fatores dificultam a adesão ao tratamento. Também chamada de aderência ou observância terapêutica, conforme osdiversos autores tratam o assunto, a adesão ao tratamento anti-retroviral é definida como a efetiva tomada da medicação anti-retroviral segundo o prescrito pelo profissional assistente.

O nível de adesão em qualquer tratamento crônico é influenciado por fatores diversos. No caso específico do tratamento contra o vírus da imunodeficiência humana (HIV), questões relacionadas à doença e ao próprio tratamento, além de situações de cunho pessoal, social ou relacionadas aos serviços de saúde, interferem no modo como os pacientes seguem a

1. Câmara dos Deputados, Brasília, DF. 2. Núcleo de Estudos de Saúde Pública, Centro de Estudos Avançados Multidiscplinares, Universidade de Brasília, Brasília, DF. 3. Departamento de Estatística, Universidade de Brasília, Brasília, DF.

Apoio Financeiro: Fundação de Apoio à Pesquisa do Distrito Federal

Endereço para correspondência: Dr. Cláudio V. Carvalho. SQS 104, Bloco J, Apto 304, Asa Sul, 70343-100 Brasília, DF.

Tel: 5561 3226-4676; Fax: 5561 3226-4990

e-mail: clviveiros@terra.com.br

Recebido para publicação em: 01/02/2007

Aceito em:17/08/2007 
prescrição médica ${ }^{134618}$. Assim, a proporção de adesão real dificilmente chega a 100\%; no entanto, uma boa adesão mostra-se ainda mais prioritária no caso do tratamento anti-retroviral, para evitar falha terapêutica e desenvolvimento de resistência do vírus aos medicamentos. Atualmente, a literatura internacional recomenda o mínimo de $95 \%$ de ingestão dos medicamentos prescritos para assegurar inibição adequada da replicação viral5 ${ }^{11} 1322$.

Existem vários métodos e técnicas para avaliar o grau de adesão ao tratamento anti-retroviral. 0 auto-relato dos pacientes vem sendo utilizado em estudos como este, devido à sua simplicidade e ao seu baixo custo. No entanto, a ocorrência de viéses de memória e a necessidade de adequação cultural para situações diversas devem ser sempre consideradas. Ainda, conforme demonstrado por Nieuwkerk e colaboradores ${ }^{20}$, quando se utiliza esta metodologia, deve ser dada atenção especial ao controle de alguns fatores inerentes ao próprio estudo - como garantia do sigilo das respostas, estabelecimento do ponto de corte para boa adesão em 95\% e caracterização da amostra pesquisada, entre outros -, para garantir a consistência dos resultados obtidos. Contudo, a técnica vem sendo bastante utilizada e se tem mostrado útil na avaliação da adesão a tratamentos crônicos ${ }^{142021}$.

No Brasil, vários estudos vêm sendo conduzidos para avaliar o grau de adesão de nossa população ao tratamento para Aids. Em 1999, um estudo multicêntrico conduzido por Nemes e colaboradores ${ }^{19}$ no Estado de São Paulo encontrou prevalência de boa adesão de $69 \%$; neste trabalho, questões relacionadas à qualidade do serviço de saúde foram o principal preditor para adesão adequada. Posteriormente, em estudo envolvendo vários estados brasileiros, a mesma autora encontrou prevalência de adesão de $75 \%$, mais uma vez sendo afetada por fatores relacionados ao serviço, porém de forma distinta. Houve também a influência de questões relacionadas ao tratamento e a características individuais ${ }^{18}$. Além desses, outros estudos de cunho quantitativo e qualitativo vêm sendo publicados em nosso meio, acerca do assunto ${ }^{12371415}$

No Distrito Federal, foi realizada apenas uma avaliação da adesão, no Centro de Saúde $n^{0}$ 1/Hospital Dia ${ }^{4}$, que à época concentrava metade dos pacientes assistidos nesta Unidade da Federação, encontrando adesão média de cerca de $86 \%$. Nesse estudo, os principais fatores determinantes do nível de adesão foram idade, escolaridade, situação de emprego, rendas pessoal e familiar, uso de substâncias ilícitas, estrutura familiar e/ou comunitária, presença de infecção oportunista no momento do diagnóstico e ocorrência de efeitos colaterais relacionados à terapia. Além desse trabalho, Vale ${ }^{27}$ realizou uma pesquisa em Taguatinga (DF), aferindo fatores associados ao abandono do tratamento de acordo com parâmetros rotineiros do serviço. Todavia, ainda não existem estudos que comparem mais de um serviço de saúde em Brasília que permitam avaliar questões mais complexas, abordando fatores relacionados a suporte social e qualidade de vida, bem como a influência da estrutura e da qualidade do serviço de saúde sobre o nível de adesão ao tratamento.

Dessa forma, o presente estudo buscou explorar possíveis fatores de risco para não adesão ao tratamento anti-retroviral, comparando as chances (odds) de exposição a esses fatores entre pacientes aderentes e não aderentes.

\section{MATERIAL E MÉTODOS}

Inicialmente, foi arrolada uma amostra seqüencial de 150 adultos que fazem uso de anti-retrovirais e são atendidos nos CR para HIV/Aids em Brasília, DF. Os dados foram obtidos por meio de entrevistas semiestruturadas e análise dos prontuários, realizados em consultório enquanto os pacientes aguardavam consulta com o médico assistente, no período de fevereiro a setembro de 2006. No período da pesquisa, havia cerca de 2.150 pacientes adultos cadastrados nas unidades de saúde do DF para receberem anti-retrovirais.

A rede da Secretaria de Estado de Saúde do DF conta atualmente com sete centros de referência em funcionamento. Desses, dois podem ser considerados clínicas especializadas CSB-01/Hospital Dia, no Plano Piloto, e Policlínica de Taguatinga, localizada na cidade satélite de Taguatinga; além dos citados, existe mais um centro de referência no Plano Piloto (CSB-11) e quatro em outras cidades satélites (CSC-01, na Ceilândia; CSG-05, no Gama; CSP-01, em Planaltina e CSS-01, em Sobradinho), que funcionam em centros de saúde da rede. 0 Hospital Universitário de Brasília (HUB), também localizado no Plano Piloto, completa a rede de centros de referência no Distrito Federal.

os centros de referência foram classificados em grandes ou pequenos, em decorrência do número de pacientes que atendiam no início do ano de 2006 e dos serviços que oferecem. Foram considerados CR de grande porte a Policlínica de Taguatinga, o CSB-01/Hospital Dia, o CSB-11 e o HUB, que atendem a mais de 150 pacientes adultos e que possuem serviços específicos, como grupos de adesão e hospital-dia, entre outros. Os demais CR atendem menos de 150 pacientes e foram, então, classificados como de pequeno porte.

Para análise da variável "bairro de residência", os locais foram classificados em Plano Piloto (Asa Sul, Asa Norte, Sudoeste), Cidades Satélites (Brazlândia, Ceilândia, Estrutural, Gama, Guará, Núcleo Bandeirante, Paranoá, Planaltina, Recanto das Emas, Samambaia, Santa Maria, São Sebastião, Sobradinho, Taguatinga), Entorno (22 municípios pertencentes à Região Integrada de Desenvolvimento do DF e Entorno - RIDE), e outros estados, excluindo a área de abrangência da RIDE.

o questionário de coleta de dados foi elaborado com a contribuição dos instrumentos construídos por Carvalho e cols ${ }^{4}$, Seidl e cols ${ }^{24}$ e Dias, citado por Ferrante e cols ${ }^{8}$, com adaptações, e utilizou a tabela de autoclassificação de raça/cor do Instituto Brasileiro de Geografia e Estatística (IBGE).

0 pré-teste foi feito com 15 pacientes atendidos no HUB; as entrevistas foram realizadas por acadêmicos da Universidade de Brasilia (UnB) treinados e acompanhados pelos autores do trabalho. Foram colhidas em dias e horários diferentes, não fixos, contemplando todas as possibilidades de horários de atendimento.

A medida de adesão foi estimada considerando o relato do número de comprimidos tomados nos sete dias anteriores à entrevista, calculando-se o percentual de comprimidos ingeridos em relação ao total prescrito. 0 parâmetro de boa adesão foi definido como a ingestão de pelo menos $95 \%$ dos comprimidos prescritos pelo médico assistente. 
Dos 150 pacientes entrevistados, 35 (23,3\%) referiram adesão inferior a 95\%, sendo considerados não aderentes e definidos como casos. Para cada caso não aderente, foram selecionados dois controles aderentes, pareados por idade i.e., pertencentes à mesma faixa etária. A maior diferença de idade entre casos e controles foi de três anos a mais ou a menos. 0 pareamento baseou-se apenas na idade dos pacientes, para permitir avaliar diferenças nos demais parâmetros, como sexo, local de proveniência ou serviço médico em que estavam sendo acompanhados.

Foram avaliadas variáveis sócio-econômicas e demográficas, de hábitos (uso de substâncias e dieta), relacionadas ao estado clínico, ao tratamento e ao serviço. Além dessas, foram formuladas 24 questões relacionadas ao suporte social, sendo que cada variável foi categorizada com respostas possíveis entre sempre e nunca ou entre totalmente e nada. De modo semelhante, foram realizadas nove perguntas sobre qualidade de vida (sempre a nunca; totalmente a nada; sim ou não e algumas com múltiplas respostas). Foram também identificadas as principais motivações alegadas pelos pacientes para o uso inadequado da medicação, bem como as estratégias utilizadas para facilitar o seu uso.

As variáveis foram posteriormente agrupadas em classes ou categorias e/ou codificadas, quando pertinente. Também foram recolhidos do prontuário parâmetros clínicos e laboratoriais no momento do diagnóstico e no momento da entrevista. A variável clínica foi a presença de infecções oportunistas; as laboratoriais foram a carga viral e a contagem de CD4 e CD8. 0 critério de melhora ou piora da carga viral foi concebido em decorrência de alterações superiores a $1 \log$.

Foram realizadas análises estatísticas bivariadas entre a variável dependente - percentual de adesão - e as variáveis preditoras, sendo calculados a Razão de Chances (Odds Ratio) e os respectivos intervalos de confiança de $95 \%$. As diferenças encontradas foram submetidas aos testes qui-quadrado MantelHaenszel e Yates, para cada possível associação. Para as variáveis numéricas, foram calculadas as medidas de tendência central e dispersão e testadas as diferenças entre os dois grupos (casos e controles). Quando as variáveis eram de distribuição não normal foi utilizado o teste não paramétrico de Kruskal-Wallis. Para as análises acima foi considerado $o$ valor $\mathrm{p}<0,05$ como limite de significância.

No modelo de regressão logística, a variável resposta (o fato de pertencer ao grupo caso ou ao grupo controle) foi classificada como "0" para os casos e "1" para os controles. Objetivou-se estabelecer um perfil, considerando as variáveis demográficas (sexo, cor, estado civil, localização do centro de referência onde está sendo atendido etc...), sócio-econômicas (escolaridade, situação de emprego e renda), de suporte social (se recebe apoio de família e de amigos etc...), de qualidade de vida, de hábitos e quanto à percepção do atendimento no serviço de saúde. Todas as 60 variáveis foram testadas; dentre elas, as efetivamente preditoras foram selecionadas pelo método Conditional Forward Stepwise e calculada a Razão de Chances ajustada. Foi estimada a razão de verossimilhança e o qui-quadrado de Wald. Em sequiência, foi efetuada a análise de correspondência ${ }^{10}$ para visualizar graficamente o perfil dos dois grupos (casos e controles), tomando em consideração as variáveis preditoras e a magnitude do seu poder discriminante.

A pesquisa foi aprovada pelos Comitês de Ética em Pesquisa da UnB (processo 028/2003) e da Fundação de Ensino e Pesquisa em Ciências da Saúde do Distrito Federal - FEPECS (processo 050/2003). A participação no trabalho foi voluntária, sendo assegurada confidencialidade quanto às informações colhidas. 0 consentimento dos sujeitos foi dado por meio da assinatura do Termo de Consentimento Livre e Esclarecido pelo participante ou seu representante legal, conforme Resolução 196/96 do Conselho Nacional de Saúde.

\section{RESULTADOS}

Das 150 pessoas entrevistadas, $76,7 \%$ apresentavam boa adesão ao tratamento anti-retroviral. A amostra estudada foi formada por todos os 35 pacientes não aderentes, classificados como casos, e 70 controles aderentes, que foram pareados pela idade.

Características demográficas e sócio-econômicas. As variáveis sócio-demográficas que se mostraram estatisticamente significativas estão descritas na Tabela 1. Conforme esperado, a idade dos casos foi semelhante à dos controles. Nos casos, variou de 23 a 54 anos, com média de 38,9 e mediana de 39 anos; entre os controles, variou de 20 a 55 anos, com média de 38,8 e mediana de 38 anos. A razão entre os sexos masculino e feminino foi de 1,67. Entre os casos, houve $24(68,6 \%)$ homens e $11(31,4 \%)$ mulheres; entre os controles, $43(61,4 \%)$ homens e $27(38,6 \%)$ mulheres. Não houve significância estatística na diferença observada entre os dois grupos quanto ao gênero.

No que diz respeito à autoclassificação de raça/cor, $47,6 \% \mathrm{da}$ amostra classificaram-se como pardo, $25,7 \%$ como branco e $20 \%$ como preto. Houve significância estatística da diferença entre os dois grupos quanto a essa variável, sendo que os indivíduos do grupo dos casos tiveram maior chance de se autoclassificarem como pretos ou brancos, enquanto o grupo de controles como pardos.

Os dois grupos apresentaram distribuição semelhante quanto ao estado civil. Cerca de metade dos indivíduos eram solteiros; perto de um terço, casados; $10 \%$ separados e 5\% viúvos. Já a distribuição quanto ao local de residência mostrou que 7,7\% moravam no Plano Piloto, 69,2\% em cidades satélites, $21,2 \%$ nos municípios do Entorno de Brasília, e 1,9\% de outros estados. Sete (20\%) dos casos eram provenientes do entorno, mas ninguém de outros estados; já entre os controles, 15 (21,4\%) vinham do entorno e dois (2,9\%) de Minas Gerais. Apenas oito indivíduos moravam no Plano Piloto, um entre os casos e sete entre os controles. Não houve diferença significativa em relação ao bairro de residência na comparação entre os grupos caso e controle.

Apesar do pequeno número de moradores do plano piloto, a maioria dos pacientes dos dois grupos era acompanhada em centros de referência nesse bairro de Brasília: 51,4\% dos casos e $71,5 \%$ dos controles. Na amostra como um todo, $64,8 \%$ eram atendidos em CR do Plano Piloto e 34,3\% das cidades satélites do DF. Além disso, um paciente do grupo controle 
Tabela 1 - Análise de associação entre as variáveis sócio-demográficas e a não-adesão ao tratamento anti-retroviral em pacientes portadores de HIV/Aids nos Centros de Referência para DST/Aids do Distrito Federal. 2006.

\begin{tabular}{|c|c|c|c|c|c|}
\hline Variável & Cruzamento & OR & IC 95\% & Valor $\mathrm{p}$ & Sig \\
\hline Sexo & masculino $\mathrm{x}$ feminino & 1,4 & $0,5-3,6$ & 0,475 & $\mathrm{~N}$ \\
\hline \multirow[t]{5}{*}{ Raça/cor } & preto $\mathrm{x}$ outros & 2,8 & $0,9-8,3$ & 0,039 & $\mathrm{~S}$ \\
\hline & pardo $\mathrm{x}$ outros & 0,2 & $0,1-0,5$ & 0,000 & $S$ \\
\hline & branco $\mathrm{x}$ outros & 3,6 & $0,3-10,1$ & 0,005 & $S$ \\
\hline & preto ou pardo $\mathrm{x}$ outros & 0,3 & $0,1-0,9$ & 0,013 & $S$ \\
\hline & preto ou branco $\mathrm{x}$ outros & 6,3 & $2,3-17,6$ & 0,000 & $S$ \\
\hline \multirow[t]{3}{*}{ Escolaridade } & analfabeto $\mathrm{x}$ outros & 3,2 & $0,4-29,4$ & 0,197 & $\mathrm{~N}$ \\
\hline & até ens. fund. comp. x ens. médio e sup. comp. & 2,7 & $1,1-7,1$ & 0,019 & $S$ \\
\hline & até ensino médio comp. $x$ ensino superior & 7,0 & $0,9-153,7$ & 0,037 & $S$ \\
\hline \multirow[t]{4}{*}{ Situação de emprego } & fixo x outros & 0,7 & $0,3-2,1$ & 0,496 & $\mathrm{~N}$ \\
\hline & desempregado x outros & 1,1 & $0,4-3,1$ & 0,904 & $\mathrm{~N}$ \\
\hline & com renda $\mathrm{x}$ outros & 1,2 & $0,5-3,5$ & 0,648 & $\mathrm{~N}$ \\
\hline & aposentado $\mathrm{x}$ outros & 1,8 & $0,6-5,2$ & 0,204 & $\mathrm{~N}$ \\
\hline CR em que faz & plano piloto $\mathrm{x}$ cidades satélites & 0,4 & $0,2-1,0$ & 0,029 & $S$ \\
\hline acompanhamento & CR grandes $\mathrm{x}$ pequenos & 0,7 & $0,2-2,6$ & 0,556 & $\mathrm{~N}$ \\
\hline Renda pessoal & $\leq 3 \mathrm{X}>3 \mathrm{SM}$ & 1,4 & $0,4-4,9$ & 0,585 & $\mathrm{~N}$ \\
\hline Renda familiar & $\leq 3 \mathrm{X}>3 \mathrm{SM}$ & 2,8 & $1,0-8,3$ & 0,029 & $S$ \\
\hline
\end{tabular}

Sig: significância estatística. N: não significante. S: significante. CR: centro de referência

fazia acompanhamento em clínica particular, porém retirava a medicação no CSB-01/HD. Ainda, somente três indivíduos não retiravam a medicação no mesmo $\mathrm{CR}$ em que faziam o acompanhamento clínico, um caso e dois controles. Comparando os dois grupos, os pacientes aderentes apresentaram maior chance de serem acompanhados no Plano Piloto que os não aderentes; não houve, no entanto, diferença quando comparamos os CR considerados grandes com os pequenos.

Quanto à escolaridade, a maioria (45,7\%) dos casos apresentava ensino fundamental incompleto; além desses, 14,3\% apresentavam ensino fundamental completo e $20 \%$, ensino médio completo. Apenas um (2,9\%) caso cursou ensino superior. Também entre os controles o nível de escolaridade mais encontrado foi ensino fundamental incompleto $(37,1 \%)$, porém o nível médio de escolaridade foi mais alto, com 14,3\% de indivíduos com ensino médio incompleto; $24,3 \%$ com ensino médio completo e $10 \%$ com curso superior completo. Quando definido como pontos de corte possuir ensino fundamental completo ou ensino médio completo, houve diferença estatisticamente significativa entre os dois grupos, com maior nível de escolaridade entre os controles - pacientes aderentes.

No que diz respeito à profissão/ocupação, no grupo dos casos houve predomínio de ocupações não manuais de rotina ou assemelhadas (28,6\%), também freqüente entre os controles (18,6\%). Além disso, $25,7 \%$ dos casos e $28,6 \%$ dos controles exerciam ocupações manuais especializadas ou assemelhadas, enquanto $25,7 \%$ dos casos e $12,9 \%$ dos controles relataram trabalhar com ocupações manuais não especializadas. Ainda, nos controles houve proporção maior de donas-de-casa $(17,1 \%)$ do que nos casos $(8,6 \%)$. Entre os controles, quatro $(5,7 \%)$ indivíduos afirmaram exercer profissão liberal, cargo de gerência ou direção ou ser proprietário de empresa de tamanho médio, enquanto nenhum caso referiu tal condição. Apenas um (2,9\%) caso referiu exercer posição mais baixa de supervisão ou inspeção de ocupações não manuais, ou ser proprietário de pequena empresa comercial, industrial, agropecuária ou assemelhada; entre os controle, sete (10\%) indivíduos referiram tal ocupação. Apesar de nenhuma das diferenças descritas apresentar significância estatística, parece haver tendência para maior chance entre os controles de serem profissionais liberais, gerentes, diretores ou proprietários de empresas de tamanho médio, estudantes ou donas de casa (OR = 0,29; IC 95\% 0,06-1,19; $\mathrm{p}=0,053)$.

Em relação à situação de emprego, 22,9\% dos casos e 27,1\% dos controles têm emprego fixo; são autônomos 11,4\% dos casos e $18,6 \%$ dos controles; estão desempregados $25,7 \%$ dos casos e $22,9 \%$ dos controles, enquanto $31,4 \%$ dos casos e $18,6 \%$ dos controles estão aposentados. Além disso, dos 24 pacientes aposentados, apenas dois declararam que sua aposentadoria não havia sido conseqüente à infecção pelo HIV, um em cada grupo. Nenhum dos cruzamentos realizados com situação de emprego demonstrou significância estatística entre os dois grupos.

A renda pessoal do grupo dos casos variou de $\mathrm{R} \$ 0,00$, seis $(17,1 \%)$ indivíduos, a $\mathbf{R} \$ 4.000,00$, um $(2,9 \%)$ indivíduo; a média foi de $\mathrm{R} \$ 666,63$, e a mediana de $\mathrm{R} \$ 400,00$. Entre os controles, variou de nenhuma renda, $10(14,3 \%)$ pessoas, a $\mathbf{R} \$ 5.500,00$, um $(1,4 \%)$ paciente; a média foi de $\mathbf{R} \$ 774,57$ e a mediana de $\mathrm{R} \$ 400,00$. Na análise bivariada, não houve diferença estatística entre os grupos em nenhum dos pontos de corte testados (um, dois, três ou dez salários mínimos). A renda familiar dos casos variou de $\mathrm{R} \$ 0,00$, duas $(5,7 \%)$ pessoas, a $\mathrm{R} \$ 6.000,00$, uma $(2,9 \%)$ 
pessoa, com média de $\mathrm{R} \$ 968,34$ e mediana de $\mathrm{R} \$ 600,00$. Para os controles, variou de $\mathrm{R} \$ 0,00$, três (4,3\%) pessoas, a $\mathrm{R} \$ 20.000,00$, uma $(1,4 \%)$ pessoa; a média foi de $\mathrm{R} \$ 1.587,14$ e a mediana $\mathrm{R} \$$ 700,00. Considerando a renda familiar, houve diferença estatística entre os grupos quando adotado o ponto de corte de três salários mínimos.

A comparação das médias de renda pessoal e familiar dos dois grupos também não mostrou significância estatística (renda pessoal, Kruskal-Wallis $\mathrm{H}=0,110, \mathrm{p}=0,741$; renda familiar, Kruskal-Wallis $\mathrm{H}=0,857, \mathrm{p}=0,355)$.

Características clínicas. 0 tempo de diagnóstico do HIV/Aids entre os pacientes arrolados como casos variou de dez meses a 18 anos, com um (2,9\%) indivíduo em cada extremo. A média foi de cinco anos e 11 meses e a mediana de seis anos. Os controles variaram de quatro meses, dois (2,9\%) indivíduos, a 24 anos, um (1,4\%) indivíduo, com média de seis anos e oito meses e mediana de seis anos.

Não houve diferença entre os grupos com relação à presença de infecções oportunistas tanto no momento do diagnóstico quanto atualmente.

A carga viral dos pacientes do grupo caso no momento do diagnóstico ou na entrada no serviço variou de indetectável a 880.000 cópias, com média de $146.871,8$ e mediana de 48.915 cópias; no momento atual, varia de indetectável a 399.847 cópias, com média de 38.293,2 e mediana de 15.500 cópias. Já entre os controles, variou de indetectável a 2.700.000 cópias no início, com média de 145.239,1 e mediana de 19.000 cópias, e varia atualmente de indetectável a 276.774, com média de 10.640,5 e mediana de 0,0 cópias. A comparação das médias de carga viral dos grupos no momento do diagnóstico ou na entrada do serviço não mostrou diferença estatística (Kruskal-Wallis H 0,867, p = 0,352); no entanto, no momento da entrevista, os controles tiveram média menor que a dos casos (Kruskal-Wallis H 4.766, $\mathrm{p}=0,029$ ).

A contagem de CD4 entre os casos no momento inicial variou de quatro a 581 células, com média de 217,1 e mediana de 158 células. No momento atual, varia de quatro a 766, com média de 277,7 e mediana de 243 células. Entre os controles, a contagem inicial variou de uma a 881 células, com média de 233,8 e mediana de 148 células, e atualmente varia de 16 a 1.253, com média de 339 e mediana de 302 células. A comparação das médias de CD4 no momento do diagnóstico ou na entrada do serviço também não mostrou diferença estatística (Kruskal-Wallis H $0,000, p=0,991)$; no entanto, no momento da entrevista, houve tendência entre os controles de apresentar média maior que a dos casos (Kruskal-Wallis H 3.053, p = 0,081).

A comparação da evolução da carga viral (em log10) e da contagem de CD 4 dos dois grupos é apresentada na Figura 1. Para cada paciente observado, o número de dias representa o intervalo de tempo entre a data de início da terapia (ou entrada no serviço) e a data mais recente do diagnóstico. Observa-se que, de um modo geral, os pacientes aderentes apresentam níveis inferiores do $\log 10$ da Carga Viral em comparação com os não aderentes, com uma diferença de $0,84 \mathrm{log}$, que se mostrou estatisticamente significante $(\mathrm{p}=0,0052)$. Já com respeito às contagens de CD4 e CD8, não foram verificadas diferenças significativas entre as tendências dos dois grupos ( $\mathrm{p}>0,18)$.

Suporte social, qualidade de vida e hábitos. As variáveis de suporte social que se mostraram estatisticamente significativas estão descritas na Tabela 2. Receber apoio dos amigos com relação às suas necessidades e poder contar com alguém que demonstre gostar de você não mostraram diferença significativa na análise bivariada. A situação de moradia também não se mostrou associada ao fato de pertencer aos dois grupos. A análise das variáveis relacionadas com qualidade de vida também não mostrou nenhuma diferença estatisticamente significativa entre os grupos.

Comparando os dois grupos, não houve diferença estatística quanto ao fato de se sentirem discriminados. Do grupo total, 64 indivíduos relataram haver sido discriminados; todavia, uma dessas pessoas afirmou que "tem-se relacionado bem com a discriminação". As situações de discriminação sofrida descritas
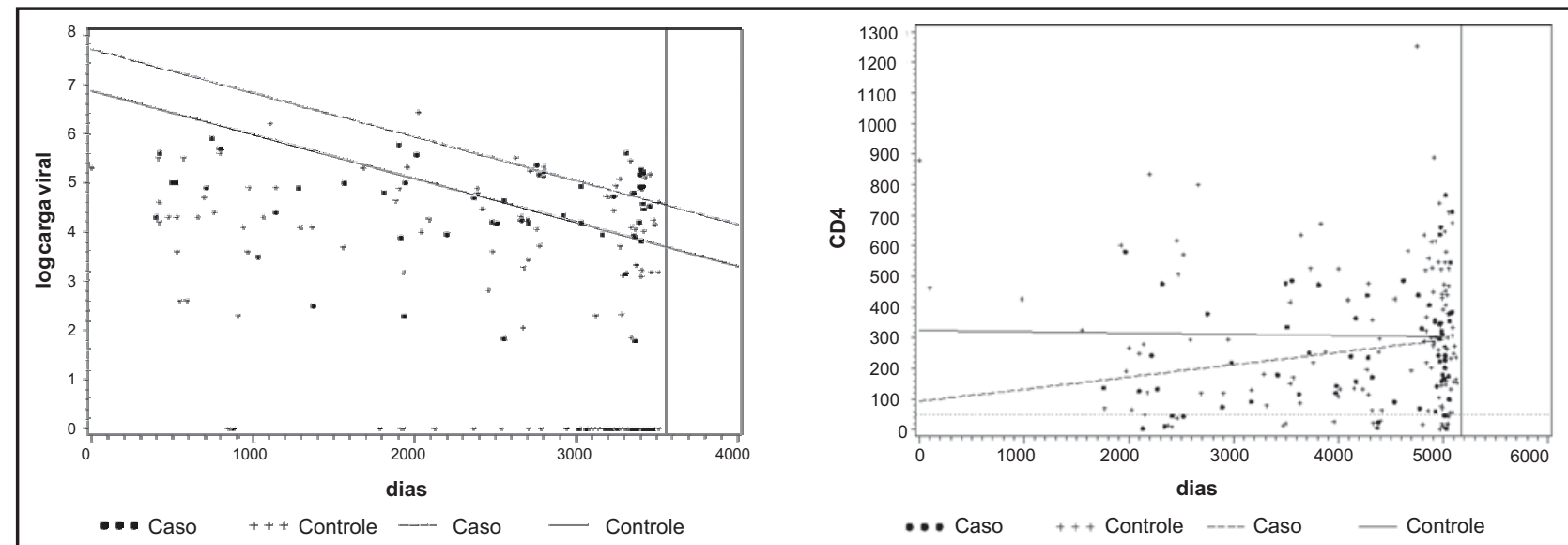

Evolução média da carga viral no grupo Caso $=\log \mathrm{CV}=7,71-0,00089 *$ dias (linha pontilhada); no grupo controle $=\log \mathrm{CV}=(7,71-0,84)-0,00089 *$ dias.

Evolução média do CD4 no grupo Caso $=92.2+0.04 *$ dias (linha pontilhada); no grupo Controle $=325.9158-0,0042 *$ dias.

Linha vertical: data 16/08/2006. Número de dias = intervalo entre a data de início da terapia e a data mais recente do diagnóstico. 


\begin{tabular}{|c|c|c|c|c|c|}
\hline Variável & Cruzamento & OR & IC (95\%) & Valor $\mathrm{p}$ & Sig \\
\hline & Variáveis do tratamento & & & & \\
\hline \multirow[t]{3}{*}{ Número de comprimidos diários } & até três $\mathrm{x}$ acima de três & 0,7 & $0,2-1,9$ & 0,442 & $\mathrm{~N}$ \\
\hline & até quatro $\mathrm{x}$ acima de quatro & 0,4 & $0,2-1,0$ & 0,039 & $S$ \\
\hline & até seis $\mathrm{x}$ acima de seis & 0,5 & $0,2-1,3$ & 0,098 & $\mathrm{~N}$ \\
\hline \multirow[t]{2}{*}{ Dificuldade para a tomada da medicação } & sim x não & 3,5 & $1,5-8,5$ & 0,007 & $S$ \\
\hline & Variáveis de suporte social & & & & \\
\hline \multirow[t]{4}{*}{ Situação de moradia } & sozinho $\mathrm{x}$ outros & 0,7 & $0,2-2,4$ & 0,56 & $\mathrm{~N}$ \\
\hline & família/companheiro(a) x outros & 0,6 & $0,2-1,4$ & 0,19 & $\mathrm{~N}$ \\
\hline & amigos/instituição x outros & 2,2 & $0,7-7,4$ & 0,19 & $\mathrm{~N}$ \\
\hline & em instituição x outros & 1.0 & $0,2-5,7$ & 1,00 & $\mathrm{~N}$ \\
\hline Apoio dos amigos às necessidades & sim x não & 0,5 & $0,2-0,3$ & 0,119 & $\mathrm{~N}$ \\
\hline Sentir-se importante para os outros & sim x não & 0,3 & $0,1-1,2$ & 0,045 & $S$ \\
\hline \multirow[t]{3}{*}{ Alguém que demonstre gostar de você } & sempre/quase sempre $\mathrm{x}$ & 6,9 & $1,5-36,3$ & 0,003 & $S$ \\
\hline & raramente/nunca & & & & \\
\hline & Percepção do atendimento & & & & \\
\hline Satisfação com a farmácia & totalmente/bastante x pouco/nada & 2,2 & $0.8-6,7$ & 0,104 & $\mathrm{~N}$ \\
\hline
\end{tabular}

OR: odds ratio (razão de chances). IC 95\%: intervalo de confiança de 95\%. Sig: significância estatística N: não significante S: significante

pelos pacientes podem ser agrupadas em: pela vizinhança/ comunidade (14 relatos); pela família (10 relatos); no serviço de saúde ou no trabalho (nove relatos cada), por amigos (oito relatos); no transporte público, ao apresentar a identificação que thes garante passe livre (seis relatos) e outros. Um paciente ligado ao Movimento dos Sem Terra referiu haver sido impelido a abandonar o acampamento em que residia, em decorrência de seu diagnóstico. Ademais, houve nove relatos de posturas discriminatórias provenientes de profissionais de saúde.

No momento da entrevista, $38,2 \%$ dos casos referiam uso de álcool, enquanto apenas $21,4 \%$ dos controles o faziam; apesar de não encontrarmos diferença estatística entre os grupos (OR = 2,27; IC 95\% 0,84-6,18; $\mathrm{p}<0,071$ ), parece haver uma tendência para maior chance de uso de bebida alcoólica entre os casos. 0 uso de tabaco foi referido por $32,4 \%$ dos casos e $27,1 \%$ dos controles, e o de outras drogas por apenas dois casos e um controle. Analisando o uso combinado de substâncias, seis dos casos e cinco dos controles referiram uso conjunto de álcool e tabaco; um controle referiu usar tabaco junto com outras drogas, e um não-aderente, álcool e drogas. Entretanto, ninguém da amostra fazia uso combinado das três substâncias. Não houve diferença estatística entre os dois grupos para nenhuma dessas variáveis, considerando seu uso isolado ou combinado.

Além disso, aproximadamente metade do grupo pesquisado referiu mudanças nos hábitos alimentares simultâneas ao tratamento, porém com distribuição homogênea entre os dois grupos.

Percepção do atendimento e do serviço de saúde. As variáveis relacionadas neste grupo não apresentaram diferenças significativas entre os dois grupos analisados. A grande maioria $(91,3 \%)$ dos indivíduos entrevistados estava bastante ou totalmente satisfeita com o serviço de saúde, com distribuição semelhante nos grupos de casos e controles.
Os motivos relatados para a escolha do CR de atendimento foram variados, mas podem ser agrupados em: bom atendimento (27 referências); localização (22 referências); profissionais de saúde (15 referências); garantia de anonimato, costume e centro de referência em que iniciou seu tratamento (10 referências cada); pelos serviços oferecidos (sete referências); é o único que conhece (quatro referências); por indicação (três referências) e outros.

Questionados, 10 indivíduos entre os casos e 17 entre os controles afirmaram haver outras consultas, além da médica. As especialidades mais referidas foram serviço social (cinco dos casos e quatro dos controles) e odontologia (um caso e seis controles).

Nível de adesão e tomada da medicação. Entre os casos, o nível de adesão estimado pelo número de comprimidos efetivamente ingeridos variou de $0 \%$, oito $(22,9 \%)$ indivíduos, a $93 \%$, quatro $(11,4 \%)$ indivíduos; a média foi de $59,6 \%$ e a mediana de $76 \%$. Os controles referiram de $95,2 \%$ de adesão, um (1,4\%) indivíduo, a 100\%, 66 (94,3\%) indivíduos; a média foi de $99,8 \%$ e a mediana de $100 \%$.

Todos os pacientes tomavam entre três e 19 comprimidos por dia. Entre os casos, a média foi de 7,3 e a mediana de seis comprimidos; entre os controles, média de 5,5 e mediana de quatro comprimidos. Os medicamentos eram consumidos em duas a cinco tomadas diárias, com média de 2,7 e mediana de duas para os casos e média de 2,6 e mediana de três para os controles. Ainda, a comparação das médias do número de comprimidos diários entre os dois grupos mostrou significância estatística (Kruskal-Wallis H 4.097, $\mathrm{p}<0,043$ ). No entanto, a comparação das médias do número de tomadas diárias não se mostrou significativa (Kruskal-Wallis H 0,009, p $<0,925$ ).

0 grupo dos casos referiu haver deixado de tomar de dois a 84 comprimidos nos últimos sete dias, com média de e mediana de 
12 comprimidos. Já entre os controles, apenas quatro indivíduos referiram haver deixado de tomar comprimidos: três pessoas não tomaram um comprimido na última semana e uma pessoa não tomou dois. Dois indivíduos do grupo dos casos referiram haver realizado todas as tomadas prescritas, porém não com todos os comprimidos esperados. Foi constatado que, em muitas ocasiões, o dado referido pelo paciente discordava daquele constante do prontuário.

0 relato de efeitos colaterais com a medicação anti-retroviral possibilitou mais de uma resposta. No grupo dos casos, $65,7 \%$ referiram ao menos um efeito colateral, com 40 relatos totais; entre os controles, 62,9\% referiram algum efeito, com 67 referências. Os principais efeitos colaterais descritos pelos casos foram classificados como neurológicos ou psiquiátricos, excetuados neuropatias e neurites periféricas (18 relatos), ou digestivos, exceto alterações hepáticas (14 relatos). No grupo controle, o perfil foi semelhante, com 30 relatos de efeitos neurológicos ou psiquiátricos, exceto neuropatias e neurites periféricas, e 23 quadros digestivos, exceto alterações hepáticas. Sete pacientes referiram lipodistrofia, um entre os casos e seis entre os controles. Nos dois grupos, Efavirenz foi o principal fármaco responsabilizado pelos efeitos colaterais, especialmente aqueles de ordem neurológica.

Pacientes dos dois grupos referiram ao menos uma dificuldade para a tomada da medicação, mas com frequiência significativamente maior entre os casos. Deles, 25 pessoas relataram 33 dificuldades; entre os controles, 29 descreveram 34 obstáculos à tomada dos medicamentos. As referências feitas podem ser categorizadas como fatores emocionais, características dos comprimidos, efeitos colaterais, esquecimento e outros, sendo bastante semelhantes nos dois grupos estudados. Foram mais relatados os efeitos colaterais, descritos por seis casos e sete controles, seguidos de quantidade de comprimidos ingeridos e esquecimento, ambos com três ocorrências entre os casos e quatro entre os controles. Cinco dos casos relataram dificuldades decorrentes do fato de estar fora de casa, como viagens ou festas, enquanto apenas um controle fez tal referência. No relato de alguns indivíduos foi verificado que não eram aderentes por não saber a forma correta de tomar a medicação ou o número de comprimidos que deveriam ingerir. Outrossim, quatro dos casos alegaram falta do medicamento, mas nenhum controle teve esse problema. Em contrapartida, oito dos controles reclamaram dos horários de tomada da medicação, enquanto apenas dois casos o fizeram.

Quanto às providências para lembrar de tomar a medicação, houve diferença entre os grupos. Os casos fizeram 28 relatos, principalmente utilização de despertadores (oito relatos) ou pedir ajuda a familiares (seis relatos). Entre os controles, houve 86 referências, principalmente o uso de despertadores (18 relatos), deixar à vista em local visível (12 relatos) ou pedir ajuda a familiares (11 relatos). Além disso, oito dos casos e 33 dos controles afirmaram lembrar-se da tomada das medicações sem ajuda, apenas pelo hábito adquirido.

\begin{tabular}{|c|c|c|c|c|c|c|c|}
\hline Variável & Cruzamento & Estimativa & Erro padrão & $\mathrm{X}^{2}$ Wald & AOR & IC $(95 \%)$ & Valor $\mathrm{p}$ \\
\hline \multicolumn{8}{|c|}{ modelagem incluindo a variável raça/cor } \\
\hline Intercepto & 一 & 4,0 & 0,9 & 18,5 & 一- & 一- & $<0,001$ \\
\hline Cor & parda x. outras & $-3,4$ & 0,8 & 17,8 & 0,0 & $0,0-0,2$ & $<0,001$ \\
\hline Localização CR & plano piloto $\mathrm{x}$. outros & $-1,3$ & 0,7 & 3,7 & 0,3 & $0,1-1,0$ & 0,055 \\
\hline Escolaridade & até $2^{\circ}$ grau x outra & 3,1 & 1,3 & 6,1 & 22,8 & $1,9-270,9$ & 0,013 \\
\hline Apoio amigos & recebe $\mathrm{x}$ não recebe & $-1,9$ & 0,7 & 7,3 & 0,1 & $0,0-0,6$ & 0,007 \\
\hline \multicolumn{8}{|c|}{ Modelagem sem incluir a variável raça/cor } \\
\hline Intercepto & 一 & $-2,3$ & 1,4 & 2,7 & 一- & 一- & 0,105 \\
\hline Localização CR & plano piloto x. outros & $-1,6$ & 0,7 & 6,0 & 0,2 & $0,1-0,7$ & 0,014 \\
\hline Escolaridade & até $1^{\circ}$ grau x outra & 2,914 & 0,951 & 9,39 & 18,4 & $2,9-118,8$ & 0,002 \\
\hline$\overline{\text { Profissão }}$ & $\begin{array}{l}\text { profissionais liberais, } \\
\text { gerentes, diretores ou } \\
\text { proprietários de empresas de } \\
\text { tamanho médio, estudantes } \\
\text { ou donas de casa x outros }\end{array}$ & $-1,8$ & 0,9 & 3,9 & 0,2 & $0,0-0,9$ & 0,047 \\
\hline Renda & & $-0,0$ & 0,0 & 7,2 & 1,0 & $1,0-1,0$ & 0,007 \\
\hline $\begin{array}{l}\text { Contar com } \\
\text { alguém que } \\
\text { demonstre } \\
\text { gostar de você }\end{array}$ & $\begin{array}{l}\text { sempre/quase sempre } x \\
\text { raramente/nunca }\end{array}$ & 2,4 & 1,0 & 5,3 & 10,6 & $1,4-79,1$ & 0,022 \\
\hline $\begin{array}{l}\text { Satisfação na } \\
\text { farmácia de } \\
\text { dispensação }\end{array}$ & $\begin{array}{l}\text { totalmente/bastante } \mathrm{x} \\
\text { pouco/nada }\end{array}$ & 3,5 & 1,0 & 12,3 & 32,5 & $4,6-227,9$ & 0,000 \\
\hline
\end{tabular}


Já quanto aos mecanismos para contornar as dificuldades quotidianas para a tomada da medicação, enquanto os casos referiram 33 estratégias, os controles relataram 67 maneiras. Os principais relatos nos dois grupos foram levar consigo a medicação para onde forem (19 dos casos e 43 dos controles) e tomar escondido os comprimidos (sete dos casos e seis dos controles).

Análises de regressão logística e de correspondência. Os perfis encontrados nas regressões logísticas estão descritos na Tabela 3. Das 60 variáveis estudadas, permaneceram no modelo apenas quatro: raça/cor, localizaçã̃o do centro de referência de atendimento, escolaridade e o fato de receber ou não apoio dos amigos quanto às suas necessidades. Comportaram-se como fator de proteção ter cor parda, ser atendido no centro de referência do Plano Piloto, ter mais do que o ensino médio completo e receber apoio dos amigos.

Em uma simulação retirando a variável raça/cor da lista, as variáveis selecionadas pelo novo modelo passam a ser: localização do centro de referência de atendimento, escolaridade, profissão, renda, frequiência com que pode contar com alguém que demonstre gostar de você e grau de satisfação com 0 atendimento na farmácia de dispensação. Nesse modelo, mostraram-se como fator de proteção: ser atendido no centro de referência do Plano Piloto; ter mais do que o ensino fundamental; poder contar com alguém que demonstre gostar de você e estar satisfeito com 0 atendimento na farmácia de dispensação, ser profissional liberal, gerente, diretor ou proprietário de empresas de tamanho médio, estudante ou dona-de-casa. Outrossim, nesse modelo, cada $\mathrm{R} \$ 1,00$ a mais na renda pessoal representa sensivelmente um fator (cumulativo) de proteção, considerando o valor da razão de chances.

0 valor $p$ em ambos os modelos é inferior a 0,008 , tanto pelo critério da máxima verossimilhança como pelo de Wald. No primeiro modelo, o percentual de concordância entre as respostas observadas e as preditas foi de $84,4 \%$, e 0 de discordância foi de 9,2\%; para o segundo modelo, foram de $85 \%$ e $14,6 \%$, respectivamente.

A Figura 2 mostra o perfil de cada grupo, por meio da distância entre os pontos considerados semelhantes. Assim, a análise de correspondência define 0 perfil característico dos pacientes do grupo controle, que é ser de cor parda, receber apoio dos amigos, ter mais do que ensino médio completo e fazer acompanhamento médico em CR localizado no Plano Piloto. Esse perfil explica $58,2 \%$ da variação total. Sem a variável raça/cor, o perfil passa a ser: mais do que ensino fundamental, acompanhamento médico em CR do Plano Piloto, renda alta e ser profissional liberal, gerente, diretor ou proprietário de empresas de tamanho médio, estudante ou dona-de-casa. Esse perfil, por sua vez, explicaria $42,5 \%$ da variação.

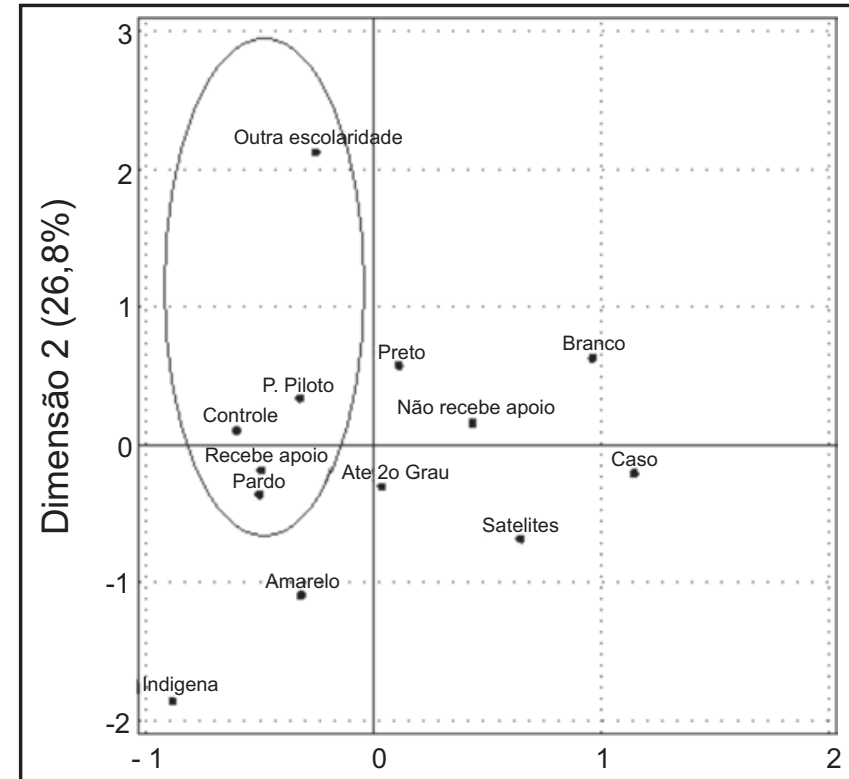

Dimensão 1 (30,4\%)

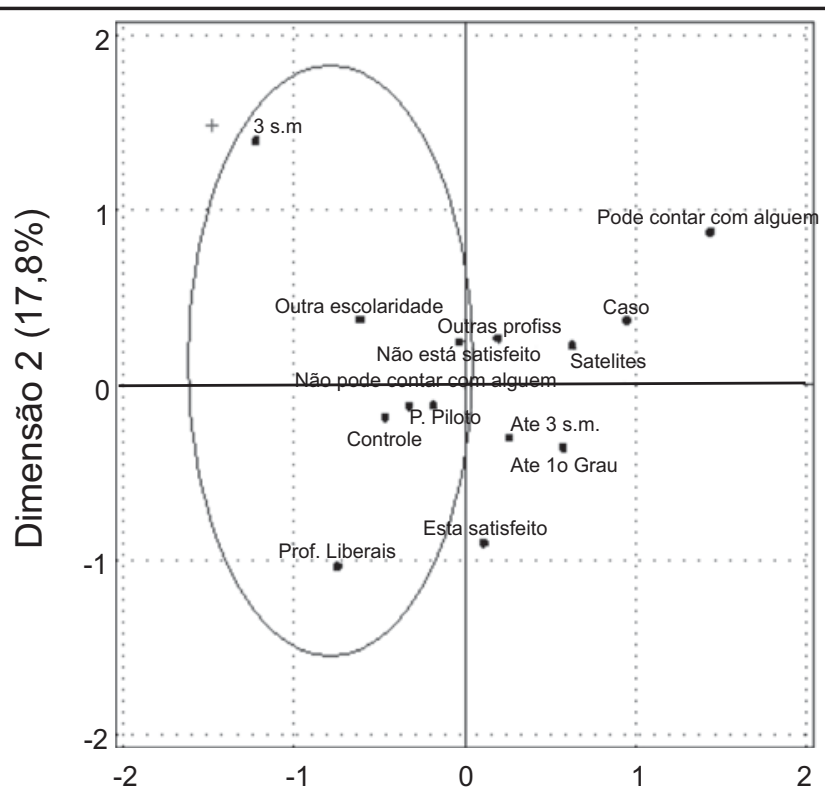

Dimensão 1 (24,7\%)

À esquerda: 0 círculo descreve o perfil que caracteriza os pacientes do grupo Controle: cor parda, apoio dos amigos, mais do que ensino médio completo e acompanhamento médico em CR do Plano Piloto.

À direita, com a retirada da variável raça/cor, o perfil que caracteriza os controles passa a ser: mais do que ensino fundamental, acompanhamento médico em CR do Plano Piloto, renda alta, ser profissional liberal, gerente, diretor ou proprietário de empresas de tamanho médio, estudante ou dona-de-casa.

Figura 2 - Mapa perceptual da análise de correspondência com base em atributos selecionados pelos modelos de regressão logística. 


\section{DISCUSSÃO}

Ao discutir os resultados obtidos, devemos inicialmente salientar algumas das limitações deste trabalho. 0s 150 pacientes entrevistados foram arrolados de forma seqüencial, portanto não aleatória. Além disso, por se tratar de um estudo do tipo caso-controle, a amostra estudada não pode ser considerada representativa da população alvo. Por esses motivos, qualquer extrapolação dos resultados da pesquisa para 0 grupo geral de pacientes de HIV/Aids que fazem uso de anti-retrovirais no DF deve ser feita com cautela. Outrossim, para a avaliação da adesão ao tratamento, consideramos apenas o relato da ingestão dos medicamentos prescritos. Não foram feitas considerações acerca do respeito ao horário de tomada da medicação ou do seguimento das eventuais restrições dietéticas necessárias, o que deve ser levado em consideração, pois a literatura aponta dificuldades para a manutenção dessas rotinas por longos períodos ${ }^{23}$. Foi tentado contornar vieses de memória limitando o período de recordação aos sete dias anteriores à entrevista.

Os dois grupos foram bastante semelhantes quanto à idade, o que sugere eficácia do pareamento realizado. A média de idade de ambos foi superior á anteriormente encontrada no DF, porém compatível com a descrita por Nemes e cols ${ }^{18}$, em estudo realizado com 1.972 pacientes de sete estados brasileiros. Isso pode ser devido ao envelhecimento da população que vive com HIV/Aids no Brasil. Cabe ressaltar que a idade média dos dois grupos foi inferior a 40 anos, o que na literatura indica maior probabilidade de não adesão ao tratamento ${ }^{1418}$.

Além disso, a razão entre os sexos masculino e feminino foi menor do que a verificada para a população do DF no estudo anterior, e próxima à encontrada no Brasil nos últimos anos - em torno de $1,5^{16}-$, o que é compatível também com a tendência de maior participação das mulheres na epidemia. Gênero, em consonância com a literatura, não se mostrou determinante para 0 nível de adesã $0^{11^{14}}{ }^{18}$. Todavia, foi encontrada uma aparente tendência a maior chance de ser homem entre os casos do que entre os controles, sugerindo menor adesão ao tratamento no sexo masculino. Tal tendência discorda da anteriormente verificada em Brasilia, onde as mulheres pareciam aderir menos ao tratamento, mesmo que nenhum trabalho haja demonstrado diferença estatisticamente significativa para essa variável ${ }^{427}$.

0 principal preditor de boa adesão encontrado foi raça/cor, permanecendo importante inclusive no modelo de regressão logística. As autodenominações preto e branco foram associadas a não adesão; já a de pardo mostrou-se associada a adesão pois os casos apresentaram chance bastante maior de serem pretos ou brancos; já os controles, de serem pardos. Como essa variável reflete de maneira indireta o nível sócio-econômico, esperaríamos encontrar maior adesão entre as pessoas de cor branca - que tendem a apresentar maior escolaridade $\mathrm{e}$ melhor situação social. Além disso, não esperaríamos resultados discordantes entre aqueles que se dizem pretos ou pardos, que tendem a apresentar situações sócio-econômicas semelhantes ${ }^{10}$. Contudo, a proporção de brancos em nossa amostra, cerca de $26 \%$, foi menor do que na população geral brasileira, que é de 53,7\%, ou do DF, que é de 49,212. Tal dado poderia justificar o resultado encontrado. Outrossim, a utilização da tabela do IBGE, que pressupõe a autoclassificação de raça/cor, confere à variável uma característica de subjetividade excessiva, podendo limitar seu poder preditivo. Por essa razão, realizamos também a regressão logística excluindo-a do modelo, com o intuito de evidenciar outras variáveis importantes e menos subjetivas.

A diferença encontrada nas variáveis sócio-econômicas entre os dois grupos é consistente com os achados de outras pesquisas $^{41718}$. Em conformidade com os trabalhos realizados anteriormente em Brasília ${ }^{427}$, baixa renda, mostrou-se associada com não adesão, sendo evidenciada no modelo de regressão logísitica. Ainda em concordância com a literatura ${ }^{214} 1826$, baixa escolaridade mostrou-se fator de risco para não adesão, mostrando-se significativa também no modelo de regressão logística e permanecendo inclusive após a retirada da variável raça/cor da análise.

Ocupações relacionadas a um melhor nível sócio-econômico mostraram-se fatores de proteção em relação à não adesão no modelo multivariado. Quanto a essa variável, foi relevante também o fato de nenhum dos indivíduos entrevistados ocupar altos cargos políticos ou administrativos, ser proprietário de grandes empresas ou assemelhados, profissões que, na classificação utilizada, representam o nível sócio-econômico mais elevado. Isto pode refletir a pauperização da população vivendo com HIV/Aids.

Ademais, chama a atenção o fato de aposentadoria ser a situação de emprego mais freqüente entre os casos, sendo decorrente do HIV/Aids em 90,1\% dos pacientes. Em contrapartida, para os controles, o mais frequiente é possuir emprego fixo. Ainda que não se possa estabelecer relação temporal de causa e efeito neste tipo de estudo, o dado pode ser explicado por um maior comprometimento do estado geral dos pacientes menos aderentes, ao menos em algum momento de sua vida, levando à aposentadoria.

A maioria dos centros de referência localizados fora do Plano Piloto corresponde a centros de saúde de pequeno porte, que podem ter menor grau de estruturação e organização. Fatores que não foram investigados nesta pesquisa, como processos de trabalho, composição das equipes, infra-estrutura, oferta de outros serviços de assistência podem explicar o fato dos pacientes do grupo controle terem maior chance de serem atendidos no Plano Piloto do que os casos. Isto ocorreu independentemente de seus locais de moradia, e essa variável permaneceu nos dois modelos de regressão logística testados. Uma das abordagens analíticas multivariadas revelou a satisfação com a farmácia de dispensação como fator associado à adesão. Isto pode refletir uma melhor organização dos serviços nesse aspecto. Apesar disso, não houve diferença estatística entre outras variáveis que pesquisamos relacionadas com os serviços de atendimento. Tal fato aponta para a necessidade de aprofundamento do assunto com novas pesquisas, uma vez que a literatura demonstra grande influência do porte e da qualidade dos serviços de saúde sobre a adesão ao tratamento anti-retroviral ${ }^{18} 19$.

Outra questão que assinala a necessidade de maior aprofundamento é a situação de moradia. Nenhum dos 
cruzamentos efetuados apontou para diferença significativa entre os grupos. Todavia, esse foi um fator que se mostrou preditor do abandono ou da não adesão ao tratamento nos trabalhos anteriormente realizados em Brasília ${ }^{42}$. Tal fato também pode ser atribuído ao tamanho da amostra, eventualmente insuficiente para explicitar a diferença de caos e controles.

A única variável clínica associada à adesão foi carga viral. Mesmo ambos os grupos havendo mostrado redução no $\log \mathrm{da}$ carga viral, os pacientes aderentes tiveram cargas mais baixas e ficaram indetectáveis em maior proporção que os não aderentes, conforme o esperado. 0 fato de a média de CD4 não haver apresentado diferença estatística também pode ser explicado pelo tamanho da amostra, uma vez que parece evidente a tendência de média maior entre os controles.

Analisando as categorias de dificuldades para a tomada da medicação, os indivíduos classificados como casos referiram, proporcionalmente, duas vezes mais dificuldades que os controles, e em situações mais variadas, o que era esperado. 0 relato de quatro indivíduos não aderentes de falta de medicamento chama a atenção, considerando que a medicação é oferecida de forma gratuita nos CR; tal fato pode significar que os pacientes não têm comparecido à farmácia de dispensação para sua retirada. Outro ponto verificado foi que alguns dos casos não estão sendo suficientemente informados sobre a forma correta de tomar a medicação.

A diferença no número de comprimidos utilizados pelos pacientes dos dois grupos confirma 0 descrito na literatura ${ }^{118}$. Esperaríamos que também o número de tomadas fosse importante para predizer o nível de adesão, pois interfere diretamente na rotina dos pacientes; no entanto, isso não se comprovou. Tal fato é importante para direcionar a escolha do esquema terapêutico a ser utilizado, priorizando esquemas de maior aceitabilidade por parte dos pacientes.

Quanto aos efeitos colaterais, os grupos apresentaram bastante semelhança tanto no número de relatos quanto nos tipos de efeitos relatados. Existem na literatura resultados discordantes a esse respeito. Enquanto alguns estudos apontam a incidência de efeitos colaterais como importante preditor de adesã $0^{1714}$, outros não encontram tal resultado ${ }^{218}$. Os pacientes aderentes mostraram um repertório maior de estratégias para lembrar a tomada da medicação e para contornar as dificuldades encontradas, sugerindo um papel mais ativo no seu tratamento.

Outro aspecto que chamou a atenção diz respeito às situações de discriminação descritas. Foi relevante o número de relatos de discriminação por pessoas próximas, como amigos, família, comunidade em que reside ou da igreja que freqüenta. Tais situações se apresentaram também no âmbito público e nos serviços de saúde. Isso mostra que se trata de um problema ainda bastante importante em nosso meio, para o qual é necessário dar reforço às ações de sensibilização e promoção da cidadania.

Finalmente, no que concerne à qualidade de vida e ao suporte social, Seidl e colaboradores ${ }^{24}$ demonstraram que tais variáveis apresentam relação com as formas de enfrentamento com que os pacientes de HIV/Aids lidam com a doença. Assim, pode-se inferir que também a adesão ao tratamento seja influenciada por tais fatores. Neste estudo, situação de moradia, receber apoio dos amigos quanto às suas necessidades, sentir-se importante para os outros e contar com alguém que demonstre gostar de você foram variáveis preditoras da adesão ao tratamento.

Conforme o esperado, foi possível detectar uma tendência a maior uso de álcool entre os pacientes não aderentes. 0 fato de, neste estudo, não haver sido encontrada diferença estatisticamente significativa pode dever-se à possibilidade de os pacientes mudarem seus hábitos após o diagnóstico da infecção pelo vírus da imunodeficiência humana, interrompendo o uso da substância. 0 estudo de Bonolo e cols ${ }^{1}$, por ser prospectivo, pode aferir o uso de álcool imediatamente antes do início da terapia, encontrando associação com a não adesão.

A presente pesquisa fornece novos dados sobre fatores associados à adesão ao tratamento anti-retroviral além dos já consolidados na literatura. Alguns fatores relacionados ao apoio no âmbito micro-social e aos serviços de assistência contribuem para a melhor observância terapêutica entre pacientes com HIV/Aids no DF. No entanto, maior detalhamento na avaliação da qualidade dos serviços de saúde e do acesso a eles ainda é necessário.

\section{AGRADECIMENTOS}

Agradecemos a grande contribuição dos acadêmicos entrevistadores; do Sr. Delmilson Lima, digitador; dos profissionais da SES-DF e do HUB/UnB, que tanto contribuíram para a execução deste trabalho e, em especial, dos pacientes, que nos confiaram sua intimidade.

\section{REFERÊNCIAS}

1. Bonolo PF, César CC, Acúrcio FA, Ceccato MG, Pádua CA, Álvares J, Campos LN, Carmo RA, Guimarães MD. Non-adherence among patients initiating antiretroviral therapy: a challenge for health professionals in Brazil. AIDS 19 (supl 4):S5-S13, 2005 .

2. Brito AM, Szwarcwald CL, Castilho EA. Fatores associados à interrupção de tratamento anti-retroviral em adultos com Aids, Rio Grande do Norte, Brasil, 1999-2002. Revista da Associação Médica Brasileira 52:86-92, 2006.

3. Cardoso GP, Arruda A. As representações sociais da soropositividade e sua relação com a observância terapêutica. Ciência \& Saúde Coletiva 10:151-162, 2005.

4. Carvalho CV, Duarte DB, Merchán-Hamann E, Bicudo E, Laguardia J. Determinantes da aderência à terapia anti-retroviral combinada em Brasília, Distrito Federal, Brasil, 1999-2000. Cadernos de Saúde Pública 19:593-604, 2003

5. Condra JH, Emini EA. Preventing HIV-1 Drug Resistance. Science \& Medicine 4:14-23, 1997.

6. Eldred L. Quantitative HIV RNA, disponível em: http://www.hopkins-Aids.edu/ publications/report/jul97_3.html\#top, acessada em 23.08.2003, 2003.

7. Gir E, Vaichulonis CG, Oliveira MD. Adesão à terapêutica anti-retroviral por indivíduos assistidos em uma instituição do interior paulista. Revista Latinoamericana de Enfermagem 13:634-641, 2005.

8. Ferrante VLS, Botta VV, Toledo BEC. Um modelo de análise sócio-econômica: construção e resultados obtidos. Revista de Saúde Pública 10:177-190, 1976.

9. Hair JF, Anderson RE Tatham RL, Black WC. Análise Multivariada de Dados.

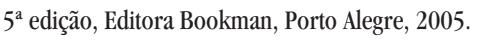


10. Heringer R. Desigualdades raciais no Brasil: síntese de indicadores e desafios no campo das políticas públicas. Cadernos de Saúde Pública 18 (supl):57-65, 2002.

11. Hirsch MS, Conway B, D'aquila RT, Johnson VA, Brun-Vézinet F, Clotet B, Demeter LM, Hammer SM, Jacobsen DM, Kuritzkes DR, Loveday C, Mellors JW, Vella S, Richman DD. Testes de resistência aos agentes anti-retrovirais nos adultos HIVpositivos. JAMA Brasil 3: 1642-1656, 1999.

12. Instituto Brasileiro de Geografia e Estatística. Censo demográfico, Rio de Janeiro, p. $1-178,2000$.

13. Katzenstein TL. Molecular biological assessment methods and understanding the course of the HIV infection. Acta Pathologica, Microbiologica et Immunologica Scandinavica 1 (supl): 1-37, 2003.

14. Lignani Júnior L, Greco DB, Carneiro M. Avaliação da aderência aos antiretrovirais em pacientes com infecção pelo HIV/Aids. Revista de Saúde Pública 35: 495-501, 2003

15. Malta M, Petersen ML, Clair S, Freitas F, Bastos F. Adherence to antiretroviral therapy: a qualitative study with physicians from Rio de Janeiro, Brazil. Cadernos de Saúde Pública 21:1424-1432, 2005.

16. Ministério da Saúde. Programa Nacional de DST e Aids. Boletim Epidemiológico - Aids e DST. Ano III - n 1 - 01 à $26^{\mathrm{a}}$ semanas epidemiológicas. Secretaria de Vigilância e em Saúde. Brasília, 2006.

17. Moralejo L, Ines S, Marcos M, Fuertes A, Luna G. Factors influencing adherence to Highly Active Antiretroviral Therapy in Spain. Current HIV Research 4:221-227, 2006.

18. Nemes MIB, Carvalho HB, Souza MFM. Antiretroviral therapy adherence in Brazil. AIDS 18 (supl):S15-S20, 2004.

19. Nemes MIB, Souza MFM, Kalichman AO, Grangeiro A, Souza RA, Lopes JF. Avaliação da aderência ao tratamento por anti-retrovirais em usuários de ambulatórios do sistema público de assistência à Aids no Estado de São Paulo. Disponível em: www.Aids.gov.br/planejamento/não_aderência.htm, acessada em 19.03.2000, 2000 .

20. Nieuwkerk PT, Oort FJ. Self-reported adherence to antiretroviral therapy for HIV-1 infection and virologic treatment response: a meta-analysis. Journal of Acquired Immune Deficiency Syndromes 38:445-448, 2005.

21. Oette M, Kroidl A, Göbels K, Stabbert A, Menge M, Sagir A, Kuschak D, O’hanley T, Bode JG, Häussinger D. Predictors of short-term success of antiretroviral therapy in HIV infection. Journal of Antimicrobial Chemotherapy 58:147-53, 2006.

22. Paterson D, Swindells S, Mohr J, Brester M, Vergis E, Squier C, Wagener M, Singh N. How much adherence is enough? A prospective study of adherence to protease inhibitor therapy using MEMScaps. In: Resumos da $6^{\text {th }}$ Conference on Retroviruses and Opportunistic Infections, Chicago, 1999.

23. Schönnesson LN, Diamond PM, Ross MW, Williams M, Bratt G. Baseline predictors of three types of antiretroviral therapy (ART) adherence: A 2-year follow-up. Aids Care 18:407-414, 2006.

24. Seidl EMF, Zannon CMLC, Tróccoli BT. Pessoas vivendo com HIV/AIDS: enfrentamento, suporte social e qualidade de vida. Psicologia: Reflexão e Crítica 18:188-195, 2005.

25. Sumartojo E. When tuberculosis treatment fails - A social behavioral account of pacient adherence. American Review of Respiratory Disease 147:1311-1320, 1993.

26. Tuboi SH, Harrison LH, Sprinz E, Albernaz RKM, Schechter M. Predictors of virologic failure in HIV-1-infected patients starting highly active antiretroviral therapy in Porto Alegre, Brazil. Journal of Acquired Immune Deficiency Syndromes 40:324-328, 2005.

27. Vale MS. Avaliação da Aderência ao Tratamento de Pacientes com HIV/AIDS no Centro de Saúde de Taguatinga No 4, Outubro - Dezembro de 1998. Monografia de Especialização. Universidade de Brasília, Brasília, DF, 1999. 